\title{
The first morphometric and phylogenetic perspective on molecular epidemiology of Echinococcus granulosus sensu lato in stray dogs in a hyperendemic Middle East focus, northwestern Iran
}

Seyyed Ali Shariatzadeh ${ }^{1+}$, Adel Spotin $^{2 \dagger}$, Shirzad Gholami ${ }^{3}$, Esmaeil Fallah ${ }^{1}$, Teimour Hazratian? ${ }^{1}$

Mahmoud Mahami-Oskouei ${ }^{1}$, Fattaneh Montazeri ${ }^{4}$, Hamid Reza Moslemzadeh ${ }^{1}$ and Abbas Shahbazi ${ }^{{ }^{*}}$

\begin{abstract}
Background: Hydatidosis is considered to be a neglected cyclo-zoonotic disease in Middle East countries particularly northwestern Iran which is caused by metacestode of tapeworm Echinococcus granulosus sensu lato. Human hydatidosis is a high public health priority in the area, however there is little known from a morphometric and phylogenetic perspective on molecular epidemiology of adult Echinococcus spp. in Iranian stray dogs.

Methods: 80 dogs (38 males and 42 females) were collected during June 2013 to April 2014 in northwestern Iran. The isolated parasites from each dog were distinguished by morphometric keys including small, large hook length and blade length. Subsequently, isolates were confirmed by sequencing of mitochondrial cytochrome oxidase subunit 1 gene.
\end{abstract}

Results: 16 (8 males and 8 females) (Prevalence $20 \%$ ) out of 80 dogs were infected to genus Echinococcus. With regard to demographic factors, the frequency of parasitism in both male, female adults and their age groups showed no difference $(P>0.05)$. The phylogenetic analyses of cox1 sequences firmly revealed the 13 sheep strains (G1), one buffalo strain (G3), one camel strain (G6) and one mixed infection. The findings of rostellar hook morphology show an intraspecies variation range among G1 isolates. However, hook measurements in Echinococcus derived from G1 (sheep strain) were not a significant difference from those G6 and G3 strains. Six unique haplotypes were identified containing a high range of diversity (Haplotype diversity 0.873 vs. Nucleotide diversity 0.02).

Conclusions: First presence of camel strain (G6) in this region seems to indicate that potential intermediate hosts play a secondary role in the maintenance of camel-dog biology. Current findings have heightened our knowledge about determination of Echinococcus prevalence, strains of taxonomy and genotypic trait of parasite in Iranian stray dogs which will also help in the development of strategies for monitoring and control of infected stray dogs in the area.

Keywords: Echinococcus granulosus sensu lato, Stray dogs, G1, G3, G6, Morphometric, Molecular-epidemiology characterization

\footnotetext{
* Correspondence: Shahbazy42@yahoo.com

${ }^{\dagger}$ Equal contributors

${ }^{5}$ Tabriz Research Centre of Infectious and Tropical Diseases, Tabriz University

of Medical Sciences, Tabriz, Iran

Full list of author information is available at the end of the article
}

() Biomed Central

(c) 2015 Shariatzadeh et al. Open Access This article is distributed under the terms of the Creative Commons Attribution 4.0 International License (http://creativecommons.org/licenses/by/4.0/), which permits unrestricted use, distribution, and reproduction in any medium, provided you give appropriate credit to the original author(s) and the source, provide a link to the Creative Commons license, and indicate if changes were made. The Creative Commons Public Domain Dedication waiver (http://creativecommons.org/publicdomain/zero/1.0/) applies to the data made available in this article, unless otherwise stated. 


\section{Background}

Uncontrolled population of infected stray dogs to parasitic infections particularly Echinococcus species in areas of increasing densities of human population is a common fact in transmission dynamics of cystic echinococcosis (CE)/hydatidosis.

Echinococcus spp. as the most important helminthesassociated zoonosis has considerable impact in disability of worldwide population in endemic areas mainly Russia, Australia, New Zealand, North Africa, South America, China, and the Middle East [1-7].

The overall annual cost of hydatidosis was estimated at US $\$ 232.3$ million in Iran [8]. Stray dogs as principal definitive hosts serve adult parasites in their intestine while herbivores as intermediate hosts harbor larval stage in their internal organs, especially lung and liver [2]. Therefore, in order to develop control, surveillance system, monitoring and preventive strategies of $\mathrm{CE}$, a better understanding of various aspects of adult E. granulosus isolates should be considered sympatrically [9-12].

Echinococcus granulosus sensu lato (s. l.) isolates show an extensive range of intraspecies variation regarding epidemiology, host specificity, morphology and genetics $[13,14]$.

Currently, four (G1, G2, G3 and G6) out of ten strains (G1-G10) of genus Echinococcus have been genotypically reported from different endemic foci of Iran [10, 15-23]. The infection rate of stray dogs with E. granulosus shows a high prevalence of $5 \%$ to $49 \%$ in different parts of Iran [24]. Nonetheless, field study problems such as trapping stray dogs, contamination with viral infections such as rabies and high risk of hydatid infection during experiments, mean there is little known about both the morphometric features and molecular-epidemiology characterization of adult E. granulosus s. $l$. in stray dogs of Iran and even around the world [25-29].

However, many investigators have been successful in their research on the metacestode stages using morphology and/or genotyping of mitochondrial genome in the intermediate hosts including sheep, buffalo, cattle, goat, pig and camels [17, 18, 30-43]. It is important to identify the genetic variation patterns of adult worms of $E$. granulosus to provide a knowledge of existing cycles in endemic foci of Iran, where several intermediate hosts are infected with CE $[21,22]$.

Therefore, the aim of this study was to investigate the morphometric and phylogenetic perspective on molecular epidemiology of $E$. granulosus s. $l$. isolates in stray dogs, in order to determine the Echinococcus prevalence, strains taxonomy and genotypic feature of isolated parasite which will help in the monitoring and control of infected stray dogs in a hyperendemic focus of Iran.

\section{Methods}

Study area, sampling and preparation

\section{Ethical approval}

The animals' collected were either dead or humanely euthanatized in the course of study with permission from appropriate authorities from the Iranian Environmental Health Organization.

Stray dogs were collected from four different regions of northwestern Iran (Fig. 1): Ahar Basmenj, Anakhatoun and Sarizamin. These are all suburb areas where livestockfarming occurs and the presence of stray and semi-feral dogs was observed. Following necropsy, the intestines of dogs were examined for adult worms of E. granulosus.

A total of 80 collected stray dogs (38 males and 42 females) were examined macroscopically during June 2013 to April 2014. First, the age and gender of trapped dogs were determined based on diagnostic criteria [44]. After physical examination, the dog's carcass in the supine position from end sections of ribs longitudinal and perpendicular was slit with the scalpel. Early the mesenteric, and then the beginning of the gastrointestinal tract alimentary canal to the end of anus were removed. To prevent removal of intestinal contents and spread of the infection thread, the double ligature technique was carried out and transferred to the laboratory. Intestines were split in an enamel basin with splitter scissors and its contents were washed with mild stream of water and passed thorough sieves containing $1 \mathrm{~mm}$ pores. Isolates were randomly separated from the small intestine of each infected dog and collected in glass containers containing $70 \%$ ethanol.

\section{Morphometric studies}

The isolated worm from each infected dog was identified by diagnostic keys as described by Khalil et al. (1994) [45] and Soulsby E.J.L. (1986) [46]. The total length of large (LTL) and small (STL) hooks, blade length of large (LBL) and small (SBL) hooks, the ratio of blade length to total length in large (LBL/LTL) and small (SBL/STL) hooks were measured using a calibrated ocular micrometer at magnifications of $100 \times$ (9.5 $\mu \mathrm{m}$ per unit space), $400 \times(2.5 \mu \mathrm{m}$ per unit space).

\section{Total genomic DNA extraction}

The measured worms were transferred into a separate tube and washed three times with normal saline and stored in $70 \%$ ethanol until molecular experiments. Genomic DNA was extracted using a High Pure PCR Template Preparation Kit (Roche, Mannheim, Germany) according to the manufacturer's instructions. 


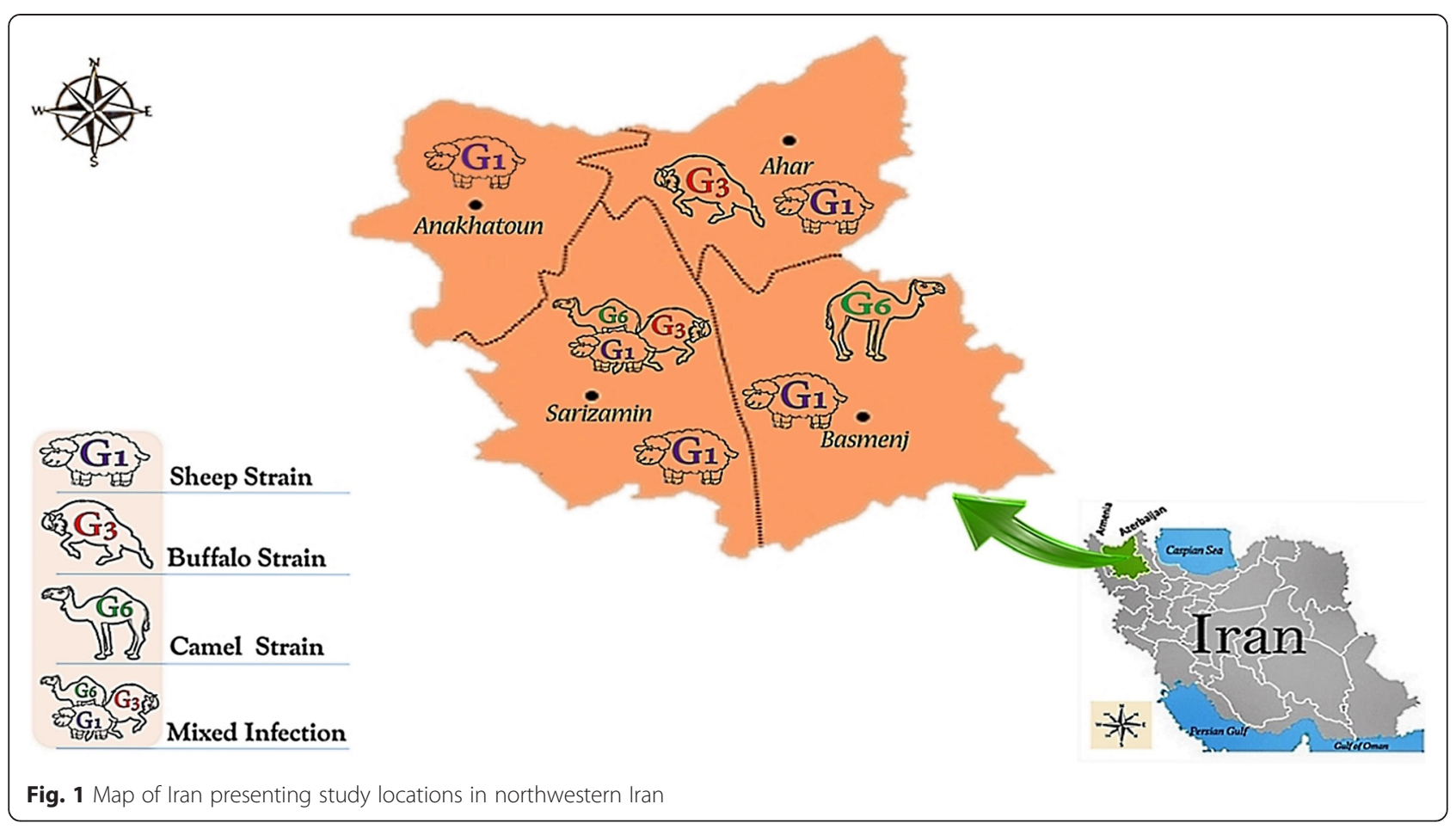

\section{PCR amplification of mitochondrial genome}

The standard PCR was employed to detect Echinococcus parasites by targeting cox 1 subunit 1 gene using the primer sets of JB3/JB4.5 [29, 47, 48].

Amplifications were performed under following PCR conditions: $94{ }^{\circ} \mathrm{C}$ for $5 \mathrm{~min}$ as an initial denaturation, $94{ }^{\circ} \mathrm{C}$ for $30 \mathrm{~s}, 50{ }^{\circ} \mathrm{C}$ for $45 \mathrm{~s}, 72^{\circ} \mathrm{C}$ for $35 \mathrm{~s}$ in 35 cycles and a final extension at $72{ }^{\circ} \mathrm{C}$ for $10 \mathrm{~min}$. PCR products were subjected to electrophoresis in $1.5 \%$ agarose gel and were observed under ultraviolet light after staining for $15 \mathrm{~min}$ with $(0.5 \mathrm{~g} / \mathrm{mL})$ ethidium bromide [47].

\section{DNA sequencing}

PCR products were purified with the Wizard SV Cleanup System (Promega). The final DNA concentration was estimated by comparison with a DNA Ladder Marker (Promega) in $2 \%$ agarosegel. All amplicons were directly sequenced by targeting cox 1 gene in both directions using the mentioned primers by ABIPRISMTM 3130 Genetic Analyzer automated sequencer (Applied Biosystem, USA). Ambiguous (heterozygous) sites were coded using the standard IUPAC codes for combinations of two or more bases. Contigs from all samples were aligned, justified and edited in consensus positions compared to GenBank sequences of all regional species using Sequencher Tmv.4.1.4 Software for PC (Gene Codes Corporation). The diversity testes of analyzed sequences (Haplotype diversity; $\mathrm{Hd}$ and Nucleotide diversity: Pi) were determined by DnaSP 5.10 .1 software [49].

\section{Haplotype network and phylogenetic analyses}

A network of mitochondrial haplotypes based on the sequences of $\operatorname{cox} 1$ using statistical parsimony was drawn by TCS 1.2 software [50]. The network estimation was run at a $95 \%$ probability limit. Confidence limits with a $95 \%$ confidence interval were established for rates of infection. To evaluate the phylogenetic information provided by cox 1 sequences a Neighbor Net network was built in Splits Tree 4.0 [51] based on genetic distances calculated according to the Kimura-2 parameter model of nucleotide substitutions.

\section{Results}

16 (8 males and 8 females) (Prevalence: $20 \%$ ) out of 80 collected stray dogs were infected with genus Echinococcus. The number of both infected and non-infected stray dogs based on their age groups and gender are shown in Table 1.

With regard to demographic factors, the frequency of parasitism in male and female adults showed no difference $(P>0.05)$, and in relation to age groups, no meaningful difference was found with contamination rate $(P>0.05)$ (Table 1).

The ranges of LHBL/LHTL and SHBL/SHTL in G1, G3 and G6 strains are summarized in Table 2. The findings of rostellar hook morphology were shown an intraspecies variation range among $\mathrm{G} 1$ isolates: $\mathrm{LHBL} / \mathrm{LHTL}=39.85 \pm 3.47 \mu \mathrm{m}$ to $45.39 \pm 3.77 \mu \mathrm{m}$ and SHBL/SHTL: $29.60 \pm 1.98 \mu \mathrm{m}$ to $39.00 \pm 3.50 \mu \mathrm{m}$. 
Table 1 Age groups and gender frequency of Echinococcus granulosus in 80 stray dogs from northwestern Iran

\begin{tabular}{|c|c|c|c|c|c|c|c|}
\hline \multirow{2}{*}{$\begin{array}{l}\text { Variables Number of stray } \\
\text { dogs }\end{array}$} & \multicolumn{3}{|l|}{ Age groups } & \multirow[t]{2}{*}{ Total } & \multicolumn{2}{|l|}{ Gender } & \multirow[t]{2}{*}{ Tota } \\
\hline & $<3$ & $3-7$ & $>7$ & & Female & Male & \\
\hline Infected to E. granulosus & $7(19.4 \%)$ & $7(22.6 \%)$ & $2(15.4 \%)$ & 16 & $8(19.0 \%)$ & $8(21.1 \%)$ & 64 \\
\hline Non- infected to E. granulosus & $29(80.6 \%)$ & $24(77.4 \%)$ & $11(84.6 \%)$ & 64 & $34(81.0 \%)$ & $30(78.9 \%)$ & 16 \\
\hline Total & 36 & 31 & 13 & 80 & 42 & 38 & 80 \\
\hline
\end{tabular}

However, hook measurements in Echinococcus derived from G1 (sheep strain) were not significantly different from those of G6 and G3 strains.

The morphological findings of rostellar hook obtained from G1 strain in the present and other studies compared to protoscolices derived from different intermediate hosts are shown in Table 3.

For all of Echinococcus isolates, fragment of $450 \mathrm{bp}$ was successfully amplified within cox 1 gene.

In this survey, Echinococcus obtained from each infected dog were directly sequenced and determined firmly as corresponding to the 13 sheep strains (G1) (in Anakhatoun, Ahar, Sarizamin and Basmenj), one buffalo strain (G3) (in Ahar), one camel strain (G6) (in Basmenj) and one mixed infection (in Sarizamin) (Fig. 1). A single-nucleotide variation (transition or transversion mutation) was identified between members of six unique haplotypes. In our targeted regions of Echinococcus DNA, insertion or deletion (Indel) mutations were not observed in E. granulosus sensu stricto (G1, G3) and E.canadensis (G6) complexes.

Synonymous substitutions exceeded non-synonymous substitutions in the $\operatorname{cox} 1$ sequences of G1, G3 and G6 genotypes. Within consensus positions, 20 point mutations were observed. Three of these were parsimonyinformative sites (24, 34 and 225 bp). Haplotype (gene) diversity $(\mathrm{Hd})$ and Nucleotide diversity $(\mathrm{Pi})$ were 0.873 and 0.02 respectively.

The nine common haplotypes AZE03 (Frequency: $56.25 \%$ ) were included without a notable heterogeneity in consensus position (GenBank Accession No; KP723338). The six unique haplotypes were included AZE11 (GenBank Accession No; KT154000) in G3 (Frequency: $6.26 \%)$, AZE01 (GenBank Accession No; KT153999), AZE02 (GenBank Accession No; KT153998), AZE04 (GenBank Accession No; KT153997), AZE05 (GenBank Accession No; KT153996) in G1 (Frequency: $25 \%$ ) and AZE10 (GenBank Accession No; KT153995) in G6 (Frequency: $6.25 \%$ ). To discern a genealogical relationship among the haplotypes, we constructed a statistical parsimony network (Fig. 2). All GenBank accession numbers for the sequences inferred from this study and for the reference genotypes/species used in phylogenetic analysis are shown in Fig. 3.

\section{Discussion}

The prevalence of Echinococcus parasites revealed a relatively high level of infection that requires an effective anti-parasite control programme. According to the studies conducted in different countries, the estimated prevalence of dog Echinococcus parasites vary from 5 to $70 \%[15,52]$, and some factors such as geographical location, sampling protocols, demographic factors, anthelmintic usage, and diagnostic techniques are responsible for the wide range of Echinococcus prevalence.

The potential role of stray dogs as definitive reservoir hosts for Echinococcosis has been recognized as a significant public health problem worldwide; however few morpho-molecular studies have been carried out based on the identification of different aspects of adult E. granulosus s. $l$. originating from stray dogs [29, 30, 53-55].

In Table 1, the lowest infection (2 of 16) was found in older dogs $(>7$ years old) than other age groups $(<3$ and 3-7) because they develop acquired immunity to reinfection in endemic areas although, no meaningful correlation was found between parasitism and age groups based on statistical analysis [56].

The infection rate of E. granulosus s. l. among stray dogs was $20 \%$ which there is no concordance with previous study (prevalence $12.5 \%$ ) [57]. It is associated with a lack of controlling infected dogs, increasing of unsanitary slaughter around the city and non-normative expulsion of infected viscera of intermediate hosts which are potential ways in transmission of disease [13, 15, 58].

It is worth mentioning that the genotyping of adult Echinococcus strains can indicate the scale of parasite biology in the region, while this shows that the intermediate hosts may acquire the infection from neighboring countries/provinces due to their immigrations and importations whereas, the stray dogs are sympatrically limited to an indigenous life $[12,13]$.

In this study, existence of genotypes G1 and G3 of $E$. granulosus show that sheep and buffalo are unambiguously circulating in the region.

In this study the camel strain was first found in a stray dog. As regards to previous reports, this seems to indicate that the role of secondary intermediate hosts (buffalo/goat/sheep/cattle) which can potentially play a role in the maintenance of camel-dog life cycle [10, 12, 59]. 
Table 2 The average morphometric criteria in Echinococcus granulosus sensu lato (G1/G3/G6) from infected dogs in the present study

\begin{tabular}{|c|c|c|c|c|c|c|c|}
\hline \multirow{2}{*}{$\begin{array}{l}\text { Number of isolated } \\
\text { strains from } 16 \\
\text { infected dogs }\end{array}$} & \multirow[t]{2}{*}{ Genotypes } & \multicolumn{3}{|c|}{ 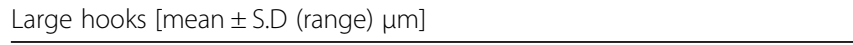 } & \multicolumn{3}{|c|}{ Small hooks [mean \pm S.D (range) $\mu \mathrm{m}$ ] } \\
\hline & & $\begin{array}{l}\text { Large hooks total } \\
\text { length (L.H.T.L) }\end{array}$ & $\begin{array}{l}\text { Large hooks blade } \\
\text { length (L.H.B.L) }\end{array}$ & LHBL/LHTL \% & $\begin{array}{l}\text { Short hooks total } \\
\text { length (S.H.T.L) }\end{array}$ & $\begin{array}{l}\text { Short hooks blade } \\
\text { length (S.H.B.L) }\end{array}$ & SHBL/SHTL \% \\
\hline 1 & G1 & $30.31 \pm 2.60\left(27.3 \_34.9\right)$ & $12.62 \pm 1.08\left(11.0 \_14.5\right)$ & $41.60 \pm 1.60$ & $20.98 \pm 2.00\left(18.0 \_23.9\right)$ & $8.10 \pm 0.71\left(6.8 \_9.2\right)$ & $39.00 \pm 3.50$ \\
\hline 2 & G1 & $33.40 \pm 3.32\left(28.5 \_38.4\right)$ & $13.07 \pm 0.73\left(12.0 \_14.4\right)$ & $39.39 \pm 3.24$ & $20.93 \pm 2.38\left(18.4 \_23.8\right)$ & $7.53 \pm 0.35\left(7.1 \_8.3\right)$ & $36.45 \pm 4.80$ \\
\hline 3 & G1 & $31.10 \pm 2.45\left(28.1 \_36.0\right)$ & $12.64 \pm 1.12\left(11.3 \_14.9\right)$ & $40.66 \pm 2.06$ & $21.60 \pm 1.70\left(19.0 \_23.4\right)$ & $7.96 \pm 0.91$ (7.0_9.3) & $36.90 \pm 3.41$ \\
\hline 4 & G1 & $29.56 \pm 1.93\left(27.0 \_33.4\right)$ & $11.93 \pm 0.67\left(11.0 \_12.7\right)$ & $40.48 \pm 2.94$ & $20.96 \pm 1.60\left(19.4 \_23.5\right)$ & $7.13 \pm 0.54\left(6.1 \_8.3\right)$ & $34.14 \pm 2.84$ \\
\hline 5 & G1 & $29.97 \pm 3.59\left(21.3 \_35.4\right)$ & $12.33 \pm 0.63\left(11.6 \_23.5\right)$ & $41.78 \pm 6.07$ & $21.67 \pm 1.57\left(19.4 \_23.7\right)$ & $7.89 \pm 0.47\left(7.12 \_8.4\right)$ & $36.68 \pm 4.32$ \\
\hline 6 & G1 & $30.66 \pm 0.73\left(29.4 \_31.4\right)$ & $12.57 \pm 0.92\left(11.3 \_13.8\right)$ & $41.01 \pm 2.67$ & $20.78 \pm 1.77\left(19.0 \_23.4\right)$ & $7.21 \pm 0.75\left(6.2 \_8.4\right)$ & $34.70 \pm 2.29$ \\
\hline 7 & G1 & $30.70 \pm 2.19\left(27.3 \_34.3\right)$ & $12.94 \pm 1.09\left(11.3 \_14.4\right)$ & $42.19 \pm 2.88$ & $22.37 \pm 1.39\left(20.3 \_25.2\right)$ & $7.00 \pm 0.44\left(6.3 \_8.0\right)$ & $31.34 \pm 1.82$ \\
\hline 8 & G1 & $31.77 \pm 1.87$ (29.1_34.5) & $12.64 \pm 1.12\left(11 \_14.7\right)$ & $39.85 \pm 3.47$ & $22.73 \pm 1.30\left(21.0 \_25.4\right)$ & $8.54 \pm 0.86$ (7.0_9.8) & $37.62 \pm 3.61$ \\
\hline 9 & G1 & $30.57 \pm 1.35$ (27.33_32.0) & $12.72 \pm 1.12\left(10.0 \_14.0\right)$ & $41.63 \pm 3.65$ & $22.63 \pm 1.12\left(21.0 \_24.8\right)$ & $7.75 \pm 0.55\left(6.7 \_8.7\right)$ & $34.26 \pm 1.96$ \\
\hline 10 & G6 & $32.50 \pm 1.35\left(30.2 \_34.4\right)$ & $13.20 \pm 1.26\left(11.3 \_14.8\right)$ & $40.66 \pm 4.06$ & $23.98 \pm 1.38\left(21.0 \_24.9\right)$ & $7.30 \pm 0.45\left(6.7 \_8.1\right)$ & $31.81 \pm 1.57$ \\
\hline 11 & G3 & $30.90 \pm 2.26\left(27.3 \_34.6\right)$ & $13.63 \pm 1.07$ (11.3_14.9) & $44.33 \pm 4.58$ & $21.93 \pm 2.00\left(19.0 \_34.3\right)$ & $7.54 \pm 1.14$ (6.1_9.0) & $34.36 \pm 3.59$ \\
\hline 12 & G1 & $32.58 \pm 2.94\left(29.0 \_38.0\right)$ & $13.67 \pm 1.08\left(11.3 \_14.9\right)$ & $40.64 \pm 4.28$ & $23.65 \pm 1.32\left(21.0 \_25.2\right)$ & $7.41 \pm 0.40$ (7.1_8.2) & $31.41 \pm 1.97$ \\
\hline 13 & G1 & $31.70 \pm 3.10\left(26.3 \_36.0\right)$ & $13.97 \pm 1.04\left(12.0 \_14.6\right)$ & $44.34 \pm 4.60$ & $22.83 \pm 1.08\left(21.4 \_24.3\right)$ & $7.01 \pm 0.76\left(6.2 \_8.3\right)$ & $30.72 \pm 2.92$ \\
\hline 14 & G1 & $30.67 \pm 1.80\left(27.3 \_33.4\right)$ & $13.58 \pm 0.76\left(12.4 \_4.8\right)$ & $44.38 \pm 3.05$ & $23.74 \pm 1.12\left(21.6 \_25.0\right)$ & $7.46 \pm 0.87$ (6.3_9.3) & $31.45 \pm 3.29$ \\
\hline 15 & G1 & $28.65 \pm 1.11\left(27.0 \_33.1\right)$ & $12.96 \pm 0.76\left(12.2 \_14.7\right)$ & $45.39 \pm 3.77$ & $22.95 \pm 1.16\left(21.0 \_25.0\right)$ & $6.79 \pm 0.50\left(6.0 \_7.3\right)$ & $29.60 \pm 1.98$ \\
\hline 16 & G1 & $31.03 \pm 2.46\left(29.0 \_36.2\right)$ & $13.66 \pm 0.75$ (12.0_14.3) & $44.33 \pm 4.79$ & $22.87 \pm 1.31\left(20.0 \_24.0\right)$ & $7.08 \pm 0.70\left(6.0 \_8.3\right)$ & $31.10 \pm 3.79$ \\
\hline
\end{tabular}


Table 3 The morphometric characteristics of the G1 genotype derived from dogs in the present study and other studies compared to protoscolices derived from intermediate hosts

\begin{tabular}{|c|c|c|c|c|c|c|c|c|}
\hline \multirow{3}{*}{$\begin{array}{l}\text { Characteristics of } \\
\text { hooks in G1 strain }\end{array}$} & \multicolumn{5}{|c|}{ ADULT (Definitive host) } & \multicolumn{3}{|c|}{ PROTOSCOLECES (Intermediate hosts) } \\
\hline & \multirow{2}{*}{$\begin{array}{l}\text { Present } \\
\text { study (Dog) }\end{array}$} & \multicolumn{3}{|c|}{ Kumaratilake et al. (1984) [55] Sheepldog origin } & \multirow{2}{*}{$\begin{array}{l}\text { Hussain et al. (2005) [54] } \\
\text { Sheepldog origin }\end{array}$} & \multirow{2}{*}{$\begin{array}{l}\text { Rajabloo et al. } \\
\text { (2012) [48] Goat }\end{array}$} & \multirow{2}{*}{$\begin{array}{l}\text { Thompson et al. } \\
\text { (1984) ref no, [74] Sheep }\end{array}$} & \multirow{2}{*}{$\begin{array}{l}\text { Gholami et al. } \\
\text { (2011) [65] Sheep }\end{array}$} \\
\hline & & Eastern Australia & Western Australia & Tasmania & & & & \\
\hline \multicolumn{9}{|l|}{ Large hook } \\
\hline Total length $(\mathrm{LTL}) \mu \mathrm{m}$ & $31.00 \pm 3.21$ & $30.5 \pm 1.8$ & $32.6 \pm 1.6$ & $34.9 \pm 1.8$ & $29.2 \pm 1.9$ & $22.93 \pm 1.68$ & $25.01 \pm 1.1$ & $26.0 \pm 1.5$ \\
\hline Blade length $(L B L) \mu m$ & $13.04 \pm 0.75$ & $12.6 \pm 0.9$ & $12.5 \pm 0.9$ & $13.8 \pm 1.1$ & & $11.25 \pm 1.35$ & $12.4 \pm 1.2$ & $13.4 \pm 1.2$ \\
\hline LBL/LTL \% & $42.04 \pm 4.79$ & $37.4 \pm 3.8$ & $37.1 \pm 4.2$ & $39.9 \pm 2.2$ & - & $49.05 \pm 4.45$ & $49.4 \pm 4.5$ & $51.5 \pm 3.4$ \\
\hline \multicolumn{9}{|l|}{ Small hook } \\
\hline Total length (STL) $\mu \mathrm{m}$ & $22.28 \pm 1.31$ & $24.3 \pm 2.3$ & $23.1 \pm 2.2$ & $30.8 \pm 3.1$ & $20.1 \pm 2.5$ & $18.7 \pm 1.7$ & $21.4 \pm 1.5$ & $22.4 \pm 1.8$ \\
\hline Blade length $(S B L) \mu m$ & $7.48 \pm 0.50$ & $9.1 \pm 1.0$ & $8.7 \pm 1.2$ & $10.4 \pm 1.7$ & 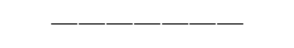 & $8.2 \pm 1.23$ & $8.5 \pm 09$ & $9.4 \pm 1.5$ \\
\hline SBL/STL \% & $33.8 \pm 1.98$ & $37.0 \pm 3.6$ & $37.9 \pm 4.1$ & $33.3 \pm 3.5$ & - - & $44.2 \pm 6.86$ & $40.6 \pm 3.5$ & $41.8 \pm 3.8$ \\
\hline
\end{tabular}




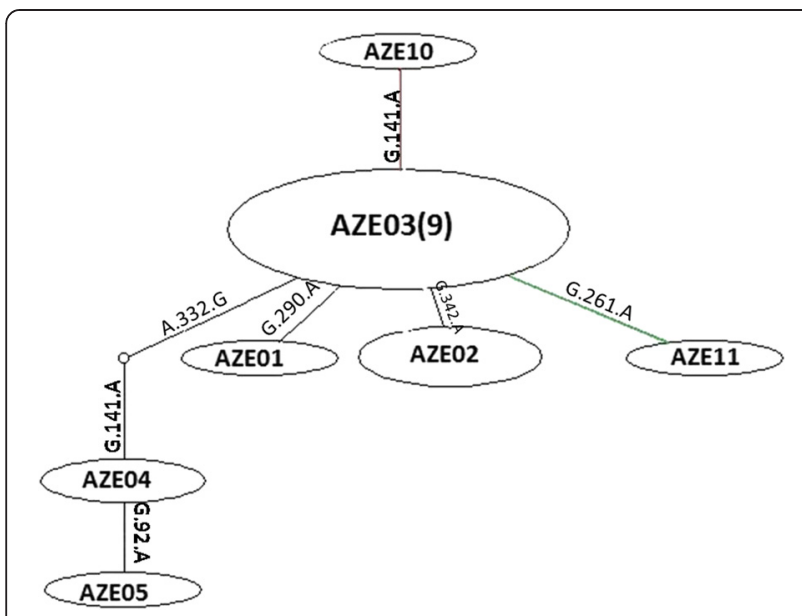

Fig. 2 Parsimonious haplotype network of mitochondrial DNA (Cox 1) obtained from the 16 sequences. The size of the circles approximately indicates the number of individuals, and each mutation event is represented on the lines by a white circle. Haplotype AZE11 in G3 strain and Haplotype AZE10 in G6 strain are charecterized by green and red lines respectively. Haplotypes AZE01, 2, 4 and 5 in G1 strain have linked to common haplotye (AZE03) by black lines

On the one hand, translocation of infected dogs from exceptional regions is the main suspected cause of the introduction of the G6 infection in the region.

In this study, presence of mixed infection of $E$. granulosus has already been explained in the liver and lungs of single animals $[60,61]$. This is described by a single infection due to a definitive host concurrently harboring adult worms of the two genotypes or due to consecutive infections of the intermediate host.

To date, the rostellar hooks morphology to be hard, not changeable, quick and inexpensive method is believed as a valid criterion for discriminating Echinococcus strains [17, 29, 37, 62-65].

Nevertheless, some researchers believe that employing morphometric criteria alone for the recognition of $E$. granulosus strains are not responsive enough and other complementary characteristics must be considered [66, 67].

The rostellar hook measurements from G1 strain were not considerably different from those G6 and G3 strains whilst, Harandi et al. [68] show that the G6 genotype is readily distinguishable from $\mathrm{G} 1$ by using both small and large hook lengths in intermediate hosts (hydatid cyst samples of livestock and human origin). They also demonstrated that the total large hook length can help to distinguish the G3 and G6 genotypes. These contradictory results are revealed by two facts. First, the morphometric keys cannot always be considered as a well-known criterion in discrimination of Echinococcus strains in both intermediate and/or definitive hosts due to various growth patterns of parasites in developmental stages (metacestode or adult). Second, due to the low number of G3 and G6 strains in this study, it should be investigated on one more sample size.

Generally, the size and shape of hooks are variable through the parasite's development which supports our findings based in Table 3. These differences may explain why dogs are usually infected with collected

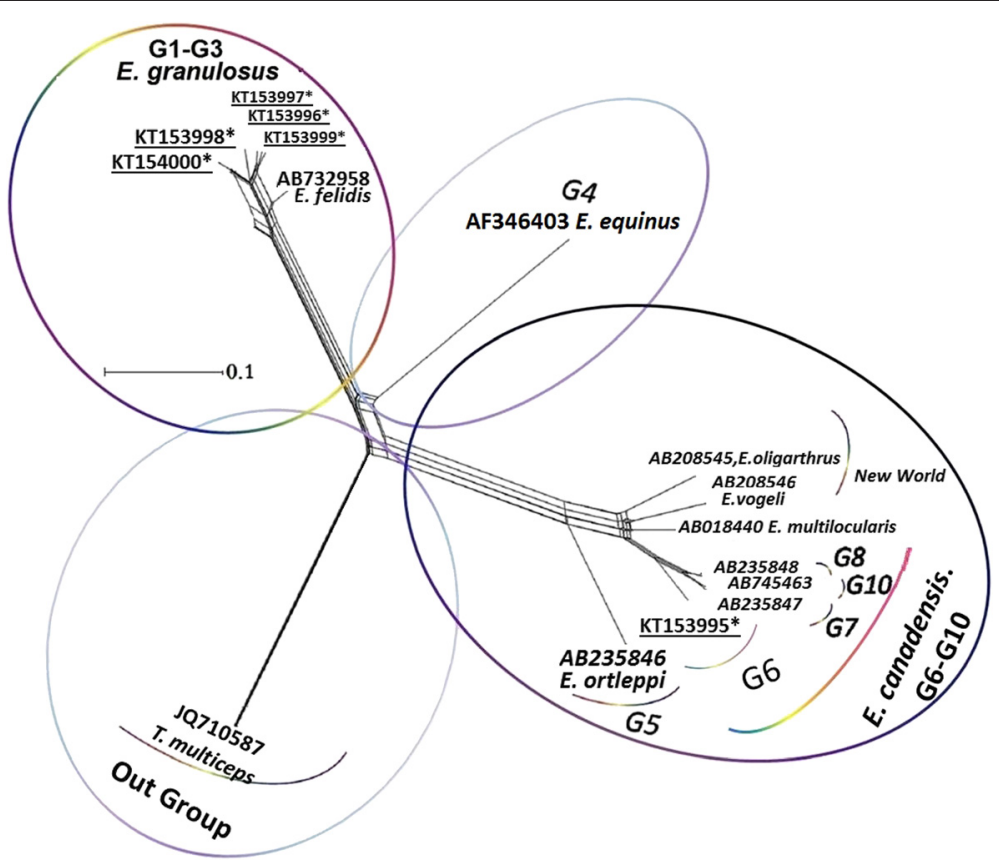

Fig. 3 NeighborNet graph according to the Kimura-2 parameter model and sequences of cox1 gene (mitogenome) of Echinococcus granulosus sensu lato. Identified strains in the present study with their submitted sequences are characterized by an asterisk $(*)$ underline 
protoscolices from several hydatid cysts, whilst the sample of protoscoleces for hook measurements frequently comes from a single cyst. However, if contamination of intermediate hosts is achieved through heterogeneous sources [30] it is probable that the hook measurements of adult worms are genetically different from the protoscoleces, and subsequently lead to differences in hook measurements.

High haplotype diversity (Hd 0.873) identified in stray dog population are alerted to pathogenecity range of $E$. granulosus/E. canadensis complexes, the creation of emergent strains in under studied areas and also the resistance of adult worms versus host innate immunity responses, including apoptosis $[6,69,70]$.

The intraspecies variations among some G1 sequences provide evidence of which mechanisms of slippage, unequal crossing over/transposition and genetic drift/ founder effect have led to the variation in Echinococcus species [71]. Also, it seems that the lack of any bottleneck effects in the under studied areas and the long term geographic segregation into the regions are probable heterogeneity assumptions [72].

\section{Conclusions}

For the first time, a relatively high prevalence of genus Echinococcus, different morphometric of sheep strain (G1) along with various strains (G1/G3/G6 and mixed infection) of $E$. granulosus s. $l$. were identified and developed by morphometric and molecular-phylogenetic taxonomic aspects in northwestern Iranian stray dogs. These findings are strengthened by our knowledge of educating the public in order to improve hygiene habits, to minimize the parasite's chance of transmission, to prevent initial contamination of the environment, controlling the size of stray dog populations, and routinely treating dogs with appropriate anthelmintic drugs. Based on recent investigations, further research will be required to determine whether the current EG95 vaccine would be effective against the E. granulosus s. $l$., or whether it will be necessary, and possible, to develop genotype-specific vaccines [73].

\section{Competing interests}

The authors declare that they have no competing interests.

\section{Authors' contributions}

SAS and AS contributed equally to this work. ASP \& ASH: contributed to the acquisition of data, carried out the molecular genetic studies and have been involved in drafting the manuscript. FM \& TH: participated in the design of the study, contributed to data collection and helped to draft the manuscript. SAS \& ASP \& MMO: performed the statistical analysis and have been involved in critically revising the manuscript for important intellectual content. SAS \& SG \& EF: participated in carrying out the molecular genetic studies. HM \& ASH: participated in the design of the study and have been involved in critically revising the manuscript. All authors read and approved the final version of the manuscript.

\section{Acknowledgements}

This study was financially supported by Faculty of Medicine, Tabriz University of Medical Sciences, Iran. This article is derived from the master's thesis of the first author (Thesis No. 92/1-3/1). We thank all staff of the Parasitology department of Mazandaran University of Medical Sciences for their collaboration.

\section{Author details}

${ }^{1}$ Department of Parasitology and Mycology, Faculty of Medicine, Tabriz University of Medical Sciences, Tabriz, Iran. ${ }^{2}$ Immunology Research Center, Tabriz University of Medical Sciences, Tabriz, Iran. ${ }^{3}$ Molecular and Cell Biology Research Center, Mazandaran University of Medical Sciences, Sari, Iran. ${ }^{4}$ Department of Parasitology, Faculty of Medical Sciences, Tarbiat Modarres University, Tehran, Iran. ${ }^{5}$ Tabriz Research Centre of Infectious and Tropical Diseases, Tabriz University of Medical Sciences, Tabriz, Iran.

Received: 22 June 2015 Accepted: 29 July 2015

Published online: 06 August 2015

\section{References}

1. Dar F, Alkarmi T. Public health aspects of cystic echinococcosis in the Arab countries. Acta Trop. 1997:67:125-32.

2. Eckert J, Deplazes P. Biological, epidemiological, and clinical aspects of echinococcosis, a zoonosis of increasing concern. Clin Microbiol Rev. 2004;17:107-35.

3. Chaâbane-Banaoues R, Oudni-M'rad M, Cabaret J, M'rad S, Mezhoud H, Babba H. Infection of dogs with Echinococcus granulosus: causes and consequences in an hyperendemic area. Parasit Vectors. 2015;8(1):1-9.

4. Moro P, Schantz PM. Echinococcosis: a review. Int J Infect Dis. 2009;13:125-33.

5. Sadjjadi SM. Present situation of echinococcosis in the Middle East and Arabic North Africa. Parasitol Int. 2006;55:S197-202.

6. Spotin A, Mokhtari Amirmajdi M, Sankian M, Varasteh A. The study of apoptotic bifunctional effects in relationship between host and parasite in cystic echinococcosis: a new approach to suppression and survival of hydatid cyst. Parasitol Res. 2012;110:1979-84.

7. Yanagida T, Mohammadzadeh T, Kamhawi S, Nakao M, Sadjjadi SM, Hijjawi $\mathrm{N}$, et al. Genetic polymorphisms of Echinococcus granulosus sensu stricto in the Middle East. Parasitol Int. 2012;61:599-603.

8. Harandi MF, Budke CM, Rostami S. The monetary burden of cystic echinococcosis in Iran. PLoS Negl Trop Dis. 2012;6:e1915.

9. Eckert J. WHO/OIE manual on echinococcosis in humans and animals: a public health problem of global concern. (2001):1.

10. Fasihi Harandi M, Hobbs R, Adams P, Mobedi I, Morgan-Ryan U, Thompson R. Molecular and morphological characterization of Echinococcus granulosus of human and animal origin in Iran. Parasitology. 2002;125:367-73.

11. Rouhani S, Parvizi P, Spotin A. Using specific synthetic peptide (p176) derived AgB 8/1-kDa accompanied by modified patient's sera: a novel hypothesis to follow-up of Cystic echinococcosis after surgery. Med Hypotheses. 2013;81:557-60.

12. Thompson RCA, Jenkins DJ. Echinococcus as a model system: biology and epidemiology. Int J Parasitol. 2014;44:865-77.

13. Thompson RCA. The taxonomy, phylogeny and transmission of Echinococcus. Exp Parasitol. 2008;119:439-46.

14. Nakao M, Lavikainen A, Yanagida T, Ito A. Phylogenetic systematics of thegenus Echinococcus (Cestoda: Taeniidae). Int J Parasitol. 2013:43:1017-29.

15. Eslami A, Hosseini SH. Echinococcus granulosus infection of farm dogs of Iran. Parasitol Res. 1998;84:205-7.

16. Zhang L, Eslami A, Hosseini S, McManus D. Indication of the presence of two distinct strains of Echinococcus granulosus in Iran by mitochondrial DNA markers. Am J Trop Med Hyg. 1998;59:171-4.

17. Ahmadi N, Dalimi A. Characterization of Echinococcus granulosus isolates from human, sheep and camel in Iran. Infect Genet Evol. 2006;6:85-90.

18. Amin Pour A, Hosseini SH, Shayan P. Comparative genotyping of Echinococcus granulosus infecting buffalo in Iran using Cox1 gene. Parasitol Res. 2011;108:1229-34.

19. Gholami S, Sosari M, Fakhar M, Sharif M, Daryani A, Hashemi M, et al. Molecular Characterization of Echinococcus granulosus from Hydatid Cysts Isolated from Human and Animals in Golestan Province, North of Iran. Iranian J Parasitol. 2012;7:8-16. 
20. Youssefi MR, Tabaripour R, Omrani VF, Spotin A, Esfandiari B. Genotypic characterization of Echinococcus granulosus in Iranian goats. Asian Pac J Trop Dis. 2013;3:362-6.

21. 21- Mahami-Oskouei M, Ghabouli Mehrabani N, Miahipour A, Fallah E. Molecular characterization and sequence analysis of Echinococcus granulosus from sheep isolates in East Azerbaijan province, northwest of Iran. J Parasit Dis 2014; 10:1007/s12639-014-0579-3

22. Shahbazi A, Mazhari N, Ghazanchaei A, Khanmohammadi M, Fallah E. Genetic variation of antigen B among Echinococcus granulosus isolates in Tabriz, East Azerbaijan, North West of Iran. J Pure Appl Microbio. 2014;8:2229-33.

23. Spotin A, Gholami S, Najafi Nasab A, Fallah E, Mahami-Oskouei M, Semnani $V$, et al. Designing and conducting in silico analysis for identifying of Echinococcus spp. with discrimination of novel haplotypes: an approach to better understanding of parasite taxonomic. Parasitol Res. 2015;114:1503-9.

24. Rokni M. Echinococcosis/hydatidosis in Iran. Iranian J Parasitol. 2009:4:1-16.

25. Abbasi I, Branzburg A, Campos-Ponce M, Hafez SKA, Raoul F, Craig PS, et al. Copro-diagnosis of Echinococcus granulosus infection in dogs by amplification of a newly identified repeated DNA sequence. Am J Trop Med Hyg. 2003;69:324-30

26. Štefanić S, Shaikenov BS, Deplazes P, Dinkel A, Torgerson PR, Mathis A. Polymerase chain reaction for detection of patent infections of Echinococcus granulosus ("sheep strain") in naturally infected dogs. Parasitol Res. 2004;92:347-51.

27. Mathis A, Deplazes P. Copro-DNA tests for diagnosis of animal taeniid cestodes. Parasitol Int. 2006;55:S87-90.

28. Hüttner M, Nakao M, Wassermann T, Siefert L, Boomker JD, Dinkel A, et al. Genetic characterization and phylogenetic position of Echinococcus felidis (Cestoda: Taeniidae) from the African lion. Int J Parasitol. 2008;38:861-8.

29. Parsa F, Fasihi Harandi M, Rostami S, Sharbatkhori M. Genotyping Echinococcus granulosus from dogs from Western Iran. Exp Parasitol. 2012;132:308-12.

30. Constantine CC, Thompson RA, Jenkins DJ, Hobbs RP, Lymbery AJ. Morphological characterization of adult Echinococcus granulosus as a means of determining transmission patterns. J Parasitol. 1993;79:57-61.

31. Eckert J, Thompson R, Lymbery A, Pawlowski Z, Gottstein B, Morgan U. Further evidence for the occurrence of a distinct strain of Echinococcus granulosus in European pigs. Parasitol Res. 1993;79:42-8.

32. Hosseini SH, Eslami A. Morphological and developmental characteristics of Echinococcus granulosus derived from sheep, cattle and camels in Iran. J Helminthol. 1998:72:337-41.

33. Ahmadi N. Using morphometry of the larval rostellar hooks to distinguish Iranian strains of Echinococcus granulosus. Ann Trop Med Parasitol. 2004;98:211-20

34. Dinkel A, Njoroge EM, Zimmermann A, Wälz M, Zeyhle E, Elmahdi IE, et al. A PCR system for detection of species and genotypes of the Echinococcus granulosus complex, with reference to the epidemiological situation in eastern Africa. Int J Paraiositol. 2004;34:645-53.

35. Lahmar S, Debbek H, Zhang L, McManus D, Souissi A, Chelly S, et al. Transmission dynamics of the Echinococcus granulosus sheep-dog strain (G1 genotype) in camels in Tunisia. Vet Parasitol. 2004;121:151-6.

36. M'rad S, Filisetti D, Oudn M, Mekki M, Belguith $M$, Nouri A, et al. Molecular evidence of ovine (G1) and camel (G6) strains of Echinococcus granulosus in Tunisia and putative role of cattle in human contamination. Vet Parasitol. 2005;129:267-72.

37. Thompson RCA, Boxell A, Ralston B, Constantine C, Hobbs R, Shury T, et al. Molecular and morphological characterization of Echinococcus in cervids from North America. Parasitology. 2006;132:439-47.

38. Villalobos N, González L, Morales J, De Aluja A, JiménezM BM, et al. Molecular identification of Echinococcus granulosus genotypes (G1 and G7) isolated from pigs in Mexico. Vet Parasitol. 2007;147:185-9.

39. Casulli A, Manfredi MT, La Rosa G, Cerbo ARD, Genchi C, Pozio E. Echinococcus ortleppi and E. granulosus G1, G2 and G3 genotypes in Italian bovines. Vet Parasitol. 2008;155:168-72.

40. Manterola C, Benavente F, Melo A, Vial M, Roa JC. Description of Echinococcus granulosus genotypes in human hydatidosis in a region of southern Chile. Parasitol Int. 2008;57:342-6.

41. Utuk AE, Simsek S, Koroglu E, McManus DP. Molecular genetic characterization of different isolates of Echinococcus granulosus in east and southeast regions of Turkey. Acta Trop. 2008;107:192-4.
42. Pednekar RP, Gatne ML, Thompson R, Traub RJ. Molecular and morphological characterisation of Echinococcus from food producing animals in India. Vet Parasitol. 2009;165:58-65.

43. Simsek S, Eroksuz Y. Occurrence and molecular characterization of Echinococcus granulosus in Turkish mouflon (Ovis gmelinii anatolica). Acta Trop. 2009;109:167-9.

44. Dyce W. Text Book Of Veterinary Anatomy. Philadelphia: Saunders press; Fourth Edition; 2010. P. 386-388.

45. Khalil LF, Jones A, Brav RA. Keys to the Cestode Parasites of Vertebrates. UK: CAB international; 1994.

46. Soulsby EJL. Helminths, arthropods and protozoa of domesticated animals. 7th ed. UK: BailliereTindall London; 1986.

47. Bowles J, Blair D, McManus DP. Genetic variants within the genus Echinococcus identified by mitochondrial DNA sequencing. Mol Biochem Parasit. 1992:54:165-73.

48. Rajabloo M, Hosseini SH, Jalousian F. Morphological and molecular characterisation of Echinococcus granulosus from goat isolates in Iran. Acta Trop. 2012;123:67-71.

49. Librado P, Rozas J. DnaSP v5: a software for comprehensive analysis of DNA polymorphism data. Bioinformatics. 2009;25(11):1451-2.

50. Clement M, Posada D, Crandall KA. TCS: a computer program to estimate gene genealogies. Mol Ecol. 2000;9(10):1657-9.

51. Huson DH, Bryant D. Application of phylogenetic networks in evolutionary studies. Mol Biol Evol. 2006;23:254-67.

52. Bugg R, Robertson I, Elliot A, Thompson R. Gastrointestinal parasites of urban dogs in Perth, Western Australia. Vet j. 1999;157(3):295-301.

53. Kumaratilake L, Thompson R, Eckert J. Echinococcus granulosus of equine origin from different countries possess uniform morphological characteristics. Int J Parasitol. 1986:16:529-40.

54. Hussain A, Maqbool A, Tanveer A, Anees A. Studies on morphology of Echinococcus granulosus from different animal-dog origin. Punjab Univ J Zool. 2005;20:151-7.

55. Kumaratilake L, Thompson R. Morphological characterisation of Australian strains of Echinococcus granulosus. Int J Parasitol. 1984;14(5):467-77.

56. World Health Organization. Report of the WHO informal working group on cystic and alveolar echninococcosis surveillance, prevention and control, with the participation of the Food and Agriculture Organization of the United Nations and the World Organisation for Animal Health. Geneva, Switzerland: Department of Control of Neglected Tropical Diseases, WHO; 2011.

57. Yagoob G, Mashaei SS. Prevalence of gastrointestinal helminthic infestation in pet and stray dogs in Tabriz (East-Azerbaijan Province), Iran. J Anim Vet Adv. 2011:10:1477-9.

58. Smith AF, Semeniuk C, Kutz SJ, Massolo A. Dog-walking behaviours affect gastrointestinal parasitism in park-attending dogs. Parasit Vectors. 2014;7(1):1-10.

59. Mehrabani NG, Kousha A, Khalili M, Oskouei MM, Mohammadzadeh M, Alizadeh S, et al. Hydatid Cyst Surgeries in Patients Referred to Hospitals in East Azerbaijan Province during 2009-2011. Iranian J Parasitol. 2014;9(2):233.

60. Casulli A, Interisano M, Sreter T, Chitimia L, Kirkova Z, La Rosa G, et al. Genetic variability of Echinococcus granulosus sensu stricto in Europe inferred by mitochondrial DNA sequences. Infection Infect Genet Evol. 2012;12(2):377-83.

61. Umhang G, Chihai O, Boué F. Molecular characterization of Echinococcus granulosus in a hyperendemic European focus, the Republic of Moldova. Parasitol Res. 2014;113(12):4371-6.

62. Gordo FP, Bandera CC. Differentiation of Spanish strains of Echinococcus granulosus using larval rostellar hook morphometry. Int J Parasitol. 1997:27:41-9.

63. Tashani O, Zhang L, Boufana B, Jegi A, McManus D. Epidemiology and strain characteristics of Echinococcus granulosus in the Benghazi area of eastern Libya. Ann Trop Med Parasitol. 2002;96:369-81.

64. Almeida FB, Rodrigues-Silva R, Neves RH, Romani EL, Machado-Silva JR. Intraspecific variation of Echinococcus granulosus in livestock from Peru. Vet Parasitol. 2007:143:50-8.

65. Gholami S, Irshadullah M, Mobedi I. Rostellar hook morphology of larval Echinococcus granulosus isolates from the Indian buffalo and Iranian sheep, cattle and camel. J Helminthol. 2011;85:239-45.

66. Rausch RL. A consideration of infraspecific categories in the genus Echinococcus Rudolphi 1801 (Cestoda: Taeniidae). J Parasitol. 1967:53:484-91.

67. Rausch RL, Nelson GS. A review of the genus Echinococcus Rudolphi 1801. Annals Ann Trop Med Parasito. 1963;57:127-35. 
68. Harandi MF, Hajialilo E, Shokouhi M. Larval Hook Length Measurement for Differentiating G1 and G6 Genotypes of Echinococcus granulosus Sensu Lato. Turkiye Parazitol Derg. 2012;36(4):215-8.

69. Amirmajdi MM, Sankian M, Mashhadi IE, Varasteh A, Vahedi F, Sadrizadeh A, et al. Apoptosis of human lymphocytes after exposure to hydatid fluid. Iranian J Parasitol. 2011:6:9-16.

70. Spotin A, Mokhtari Amirmajdi M, Sankian M, Varasteh A, Shamsian A, Vahedi F. Expression of Apoptosis Inducing-Ligands, TRAlL and Fas-L in Hydatid Cyst Germinal Layer and Normal Tissue. J Ardabil Univ Med Sci. 2012;12(1):7-15.

71. Van Herwerden L, Gasser RB, Blair D. ITS-1 ribosomal DNA sequence variants are maintained in different species and strains of Echinococcus. Int J Parasitol. 2000:30:157-69.

72. Nakao M, Li T, Han X, Ma X, Xiao N, Qiu J, et al. Genetic polymorphisms of Echinococcus tapeworms in China as determined by mitochondrial and nuclear DNA sequences. Int J Parasitol. 2010;40(3):379-85.

73. Rojas CAA, Romig T, Lightowlers MW. Echinococcus granulosus sensu lato genotypes infecting humans-review of current knowledge. Int J Parasitol. 2014:44(1):9-18

74. Thompson RCA, Kumaratilake LM, Eckert J. Observations on Echinococcus granulosus of cattle origin in Switzerland. Int J Parasitol. 1984;14:283-91.

\section{Submit your next manuscript to BioMed Central and take full advantage of:}

- Convenient online submission

- Thorough peer review

- No space constraints or color figure charges

- Immediate publication on acceptance

- Inclusion in PubMed, CAS, Scopus and Google Scholar

- Research which is freely available for redistribution 